\title{
STUDENTS WITH BEHAVIOUR DIFFICULTIES AND LATVIAN TEACHER BELIEFS ABOUT THEM: GLOBALISATION OR GLOCALISATION IN ACTION?
}

\author{
Ilona Bruveris \\ University of Notre Dame, Australia
}

\begin{abstract}
This paper analyses Latvian teacher beliefs about students with behaviour difficulties to ascertain whether the same issues are of concern for Latvian teachers as teachers from another system, such as Australia. Do they identify similar behaviours as of concern, do they have similar expectations and views about educating these students or are they so dissimilar that they, by borrowing from elsewhere, end up importing surrogate values and impossible solutions? This rests within a context of globalisation in education which encourages teachers to look to and borrow from foreign systems as an astute way of providing pre-tested solutions for local needs.
\end{abstract}

Keywords: student behaviour, teacher beliefs.

\section{Introduction}

Latvian teachers need to address student behaviours which they have previously not encountered as the students themselves, struggling with concepts of democracy, often replace the word "democracy" with the word "freedom" and do not understand that rights also entail responsibilities. Globalisation in education encourages the sharing of ideas, strategies, educational philosophies and theories. Potentially, the knowledge from one system could be used by teachers to introduce innovative practices in their own classrooms and to better understand their own systems. However, knowledge gained from one system may not transfer readily to another setting. Crucial to the borrowing process for Latvian teachers is their understanding of their own beliefs and substructures and how they may differ from those of other systems. Belief systems are important as they help teachers to define and understand themselves and their schools, students, the context. They play a role in determining what behaviours teachers will use, the meaning that they give to the term pedagogy, how they organise knowledge and how they analyse the behaviours they experience in their classrooms. Belief systems help teachers to address new situations with which they are unfamiliar, such as the range of student behaviours that teachers in Latvia now face. However to make changes to these existing belief systems, 
Ilona Bruveris. Students with Behaviour Difficulties and Latvian Teacher Beliefs about them: Globalisation or Glocalisation in Action?

teachers must first be aware of them and their substructures. Nespor (1997) concluded that beliefs are a strong predictor of behaviour, more so than knowledge, and impact upon how teachers respond to problems.

\section{Aim of the study}

This study aims to identify Latvian teacher beliefs about managing students with behaviour difficulties and to establish whether currently held beliefs allow teachers to implement practices from elsewhere in their classrooms.

\section{Method}

This study draws on research conducted with participants of two behaviour Management Professional Learning projects (Agreement No 2010/0330/1DP / 1.2.2.4.1/10/IPIA/VIAA/001) in Latvia in 2012 organised by VISC, the National Centre for Education. Each course consisted of 24 hours of lectures and workshops and a total of 110 teachers attended. Data on teacher beliefs was available from analysis of teacher reflection in response to specific questions on their expectations about student behaviour and the strategies they believed most appropriate. At the conclusion of the course, teachers were also required to collect data on student behaviour in their classrooms, identify, select and implement strategies from those presented during the course, analyse the usefulness of the strategies, identify any changes needed for implementation and report on the success of the implementation. All of this provided information on teacher perceptions of the relevance of global strategies for their specific settings as the course was based on a broad cross-section of frequently used Western behaviour management theories.

Qualitative data analysis consisted of a process of comparison and identification of recurring themes. Data was collected through initial evaluations of the course by participants; their written reflections; and, the questions raised during the course. Basic categories were created through content analysis of literature and logical groupings. Grids were created which recorded teacher beliefs concerning each of the following: strategies to maintain a positive classroom community; to encourage appropriate behaviour; to reduce inappropriate behaviour. Teacher responses were recorded on these grids in rows responding to specific categories such as teacher-parent relationships, teacher-student relationships, teacher behaviours, classroom organisation, establishment of rules, individual intervention plans, teaching/learning tasks, involvement of support staff and other agencies. 
By reading the strategies and concepts off the grid, it was possible to establish relationships between the responses and to identify reciprocal strategies and concepts. This allowed for the creation of a refined list of favoured strategies and associated beliefs.

\section{Are the issues the same?}

Literature from Western countries demonstrates that the behaviours that are of most concern in these countries are relatively trivial. It is their frequency that leads teachers to be most concerned with the low level behaviours. In the UK concern about levels of student violence led to the Elton Enquiry into discipline in schools (Department of Education and Science, 1989). Contrary to concerns raised by the media about violent behaviour, the behaviours that were identified as most of concern were 'talking out of turn' or "calling out" as identified in US studies, 'hindering other pupils', 'calculated idleness or work avoidance' and 'verbal abuse towards other pupils'. Similar results were identified in Australian research by Stephenson, Linfoot and Martin (2000) which showed that different forms of behaviour such as distractibility and hindering others cause teachers greatest concern. Beaman (2006) investigated troublesome behaviour in secondary schools in NSW where "talking out of turn" was identified by teachers as the behaviour of most concern and also as the main behaviour of the most troublesome students. Interestingly, Infantino and Little (2005) note that students also identified this behaviour as the most troublesome and most frequent. A literature review by Beaman, Wheldall and Kemp (2007) confirmed that the main classroom disruptions are relatively trivial such as "talking out of turn".

Latvian teachers have identified similar issues with respect to behaviour. In a questionnaire completed as part of the VISC Behaviour Management Professional Learning programs undertaken in 2012, teachers identified the following behaviours as most desirable: students seek help with arguments and conflict, they are friendly and courteous and they follow the rules especially, taking turns, listening to the teacher and raising their hand. They added that they wanted students to take responsibility for their behaviour. As with teachers elsewhere, the focus is on low-level behaviours not on violent and aggressive acts.

It would seem then that the problems are shared, therefore looking to previously identified solutions from elsewhere might be an appropriate strategy and lead to innovative practices in Latvian classrooms with respect to behaviour management. However when considering possible solutions, thought must be given to factors which might impact on teacher ability to implement these new practices, especially that of teacher beliefs. The remainder of this article will 
Ilona Bruveris. Students with Behaviour Difficulties and Latvian Teacher Beliefs about them: Globalisation or Glocalisation in Action?

focus upon some factors which impact upon teacher beliefs and how Latvian teacher beliefs are expressed in preferred strategies.

\section{Teacher beliefs}

Students with behaviour difficulties need a supportive environment, one that fosters belonging and engagement. Fredericks et al (2004) identified teacher support, classroom structure and positive relationships between the teacher and students as important for engagement. Whether or not a teacher can create these supportive conditions and the way that he/she teaches will depend on his/her beliefs (Guskey, 2002; Palak \& Walls, 2009). Kagan (1992, 85) stressed the importance of teacher beliefs suggesting that beliefs may lie at the very heart of teaching. Such beliefs are far reaching and include the teacher's perception about teaching, about themselves as teachers and about students with behaviour difficulties. Beliefs, in turn, affect behaviour (Levin et al., 2005). Teacher beliefs impact on what teachers teach and how they teach, as well as being passed on by teachers to their students.

Richardson (1996) defined beliefs as "psychologically held understandings, premises, or propositions about the world that are felt to be true" (p. 103) and suggested that attitudes and beliefs are important concepts in understanding the thought processes and classroom practices of teachers.

Obviously beliefs may vary. Richardson (1996) suggests that they arise from a variety of sources including personal life experience, experience with schooling and instruction and experience with formal knowledge. Other studies have identified the quality of pre-service learning and reflection on the preservice experience as affecting teacher beliefs (Brousseau, Book, \& Byers, 1998). To this list must be added the unintentional maintenance of existing beliefs by education department policies or approaches.

Teacher beliefs, potentially, could explain any divergence between the strategies that teachers from a Western system such as NSW, for example, are prepared to implement to those in Latvia. The life experiences of teachers in NSW varies markedly from those in Latvia. Putting aside the variance of individual experiences of each and every teacher, at a universal level Australian teachers have worked within a stable political democracy with gradual social changes. Latvian teachers have experienced a plural democracy, authoritarian government, including a period of colonisation, and then a return to democracy marked by neo-liberal tendencies, all within the space of one lifetime. Perhaps the only common feature to both is the neo-liberal context, as this has dominated Australian education since the 1980s. 
The relative political stability in NSW has allowed for a co-ordinated approach to achieving changes in teacher thinking and beliefs. Changes which have required teachers to undergo a paradigm shift, such as in the management of students with behaviour difficulties, have been associated with professional learning opportunities and over the decades professional learning has become linked to the needs of the system, the region, the school and the teacher. In order to achieve a paradigm shift, policies and strategic documents provide the new direction, school plans have to reflect this and professional learning support it. While not all teachers may have engaged with the changes or achieved a paradigm shift with respect to students with behaviour difficulties, there has been an ongoing and co-ordinated emphasis on policies and professional learning over many decades of a neo-liberal approach which has addressed teacher beliefs.

Professional learning is available to teachers in Latvia and is necessary for maintenance of their teaching accreditation. The difference lies in the number of different political, at times conflicting, directions that teachers have been exposed to in Latvia and the lack of a co-ordinated and directed approach which facilitates a paradigm shift.

\section{Teacher beliefs about pedagogy}

To this must be added differences in what must be taught. The NSW education system stresses educating citizens who can contribute to the functioning of a democracy. The importance of contributing to the political decision-making process in Australia is demonstrated by the requirement for all citizens to vote in elections at a local, state and commonwealth level. Voting is compulsory and students are educated to understand and participate in the political process, to question and to analyse.

Set against this the aims of education under a soviet system, where the important feature was to maintain and promote the approaches of the Soviet government, to preserve the status quo. Teachers were expected to promote a Soviet lifestyle and the development of a questioning and politically aware populace was not the key. The life experiences of teachers within these two systems were almost diametrically opposed.

Older teachers in Latvia would also recall teaching within a pluralistic democracy and younger teachers would have the experience of teaching within a fledgling democracy but still caught up in structures from the old soviet system. While students in NSW were educated in democratic principles, students in Latvia, after the return to independence, struggled to understand democracy. Teachers in Latvia had to come to terms with understanding not only the systems changes from their own perspectives but also how to support students in 
Ilona Bruveris. Students with Behaviour Difficulties and Latvian Teacher Beliefs about them: Globalisation or Glocalisation in Action?

making meaning from the terms "personal freedom" and "democracy" all within a context of student behaviours that were new to their experiences and where, for instance, the beliefs upheld during the soviet years did little to explain or manage these challenges.

Hansen (2012,) states "We should examine how the teacher constructs categories, teaching and classroom,". Herein arises a pointed difference between the concepts to which teachers in NSW and those in Latvia are exposed. The concept of pedagogy is promoted differently in both contexts. In Latvia pedagogy is all-inclusive, it is about educating and raising the total child (Collinson et al., 2009). Pedagogy in Western literature is often discussed as the art or craft of teaching. If Latvian teachers are constructing their classrooms based on concepts of teaching using a pedagogy that focuses on "audzināšana", loosely translated as upbringing in English, this classroom could differ from the Western classroom where the teacher is focussed on how and what is being taught, the techniques used and increasingly, performance in standardised tests. This different understanding of pedagogy would impact on teacher beliefs and what a teacher chooses to implement when exposed to innovative practices from elsewhere.

\section{Teacher beliefs and the dominant discourse}

If, as Ainscow and Sandill (2010) state, “...the starting point must be with staff members...This may also involve tackling taken for granted assumptions, most often relating to expectations about certain groups of students, their capabilities and behaviours", what factors beyond the political context and understanding of pedagogy impact on the development of these assumptions and expectations? Some beliefs are inadvertently reinforced by the policies of the system itself, with the use of labels for students with additional needs as an example.

Foucault (1974) describes how discursive practices 'form(s) the objects of which they speak." To define students with disabilities, including those with emotional or behavioural disorders (EBD), special education drew on discourses from medicine and psychology. The medical model focussed on a causal relationship. As Harry and Klinger $(2007,16)$ state, there had to be 'proof of intrinsic deficit' in order to gain access to support services.

This deficit model has consequences for both teachers and students. As Sullivan, Johnson, Owens and Conway note: "A concern raised about mainstream policies and practices related to student behaviour is that they invariably locate 'the problem' within individual students, rather than in the context of classrooms" (2014) therefore the responsibility for change rests with 
the student. The ultimate effect can also be that teachers start believing that they are not qualified to teach these children Slee (2009).

Labelling contributed to the belief amongst NSW teachers that students with additional needs did not belong in a regular classroom either because their own education suffered or that of their peers did. In NSW, special education classrooms became 'dumping grounds for those students viewed as untouchable or undesirable' (Reddy 1999, 11). Students suffered because often they experienced lowered expectations with respect to their academic and social achievements (Van Swet et al.). Metcalf (VS1995) noted that students often ended up living up to their labels and that they were often not expected to display normal, responsible behaviour.

Labelling impacts on teacher beliefs in another way as well. In NSW students with behaviour difficulties were either treated as if they have a disability and labelled EBD, or they were not considered to meet any of the disability criteria and therefore teachers viewed them as just naughty or difficult students. Without the redeeming feature of a label, they earn a quasi-label such as rude, disruptive, disobedient, ill-disciplined etc. If teachers believe that students are choosing to misbehave, then this impacts on how they interact with these students and what actions they are prepared to take and works against any paradigm shift by teachers.

A change in the dominant discourse came with the World Health Organization's (WHO) revision in 2001 of the International Classification of Functioning, Disability and Health (ICF). Rather than the cause, the impact had to be considered. This required a shift in beliefs amongst teachers. Adjustments to the teaching/learning program had to consider the situation rather than just the student's deficit.

A decree, however, does not mean a change in teacher beliefs or actions. For this to happen the teacher needs to undergo new experiences and reflect, to understand what beliefs they currently hold and what beliefs underlie the changes. In NSW statewide policies, strategic documents and professional learning strategies have been used to build new belief subcultures, to move teachers to an understanding that meeting the needs of students with behaviour difficulties requires reflection on, and examination of, the total environment and responsibility does not rest with the student alone.

While NSW has now moved away from a medical model to a social model for addressing the needs of students with additional support needs, in Latvia it is the role of the State Pedagogical Medical Commission or local government pedagogical medical commissions under the jurisdiction of the Cabinet of Ministers (General Education Law, 1999) to ensure that students with special needs can access a quality education based on equality and equal rights. These commissions determine who meets the special needs criteria and can access 
Ilona Bruveris. Students with Behaviour Difficulties and Latvian Teacher Beliefs about them: Globalisation or Glocalisation in Action?

additional or different services and it is interesting to note that a medical commission continues to make judgements about educational placement. Of concern is the perpetuation of belief systems which underpin the acceptance of the use of medical or psychological labels for educational purposes. (Erten \& Savage, 2012)

\section{Latvian teacher beliefs about intervention strategies for students with behaviour difficulties}

As Fulham and Hargreaves $(1991,5)$ point out, teachers need to be provided with opportunities to "confront the assumptions and beliefs underlying their practices, avoid faddism". The VISC project provided an opportunity to do this.

When, as part of the VISC project, Latvian teachers were asked to reflect on their own needs within the classroom, interestingly their responses did not focus on additional support such as extra resources in the classroom or smaller class sizes. Instead their needs were defined by what they could do and how they impacted on student behaviour, such as being organised, or, what they needed their students to do, such as follow the rules and take some responsibility for their own behaviours.

Teachers stressed awareness of their own behaviours as important. They indicated that interactions with students should be based on a good understanding of the student, his/her learning and behaviour needs and any specific health needs. They believed that interactions with students should be firm, but friendly and that teachers could be positive role models. They also saw themselves assisting students to resolve problems and suggested that teaching students to be optimistic would help.

They believed that they could develop good rapport with students through demonstrating their interest in the student's activities and showing that they cared about the student. They also suggested that teachers should ensure that students with behaviour difficulties had positive experiences at school each day and they should avoid referring to past negative behaviours. Positive interactions could also be created by devising classroom rules jointly with the students, informing parents of these rules and encouraging parents to follow the same rules if appropriate.

Interactions surrounding learning tasks were also seen as important for creating a positive classroom environment. They believed that teachers should manage learning tasks so that they were varied, designed to meet individual student need and provided the student with choices. Teachers suggested that developing a systematic way of providing feedback would also help to support teacher/student interactions, as would keeping a record of appropriate 
behaviours rather than just inappropriate ones. As well they stressed the importance of the task itself, not just finishing it.

While all of these strategies would help to create a positive environment, there would be times when some form of direct intervention was needed. At such times they suggested that teachers should observe the student in class which would provide data for the development of any intervention plans. By doing this teachers would gather information and make educated decisions about the nature of the behaviour and any necessary intervention. There was a focus on private interactions, from preventative strategies like using private cues to prompt students, to engaging students in private discussions to address behaviour problems.

Having good relationships with students and their parents was seen as crucial. These good relationships could be maintained by using humour and remaining calm in class. Teachers suggested a focus on current behaviour issues rather than re-visiting past problems. They also indicated that praise should be used to encourage students to improve their behaviour.

However teachers must maintain control in the classroom and not give it over to the student. They believed teachers could best do this by using consequences consistently, as well as proximity as a deterrent. Again there was a focus on the positive. Teachers need to be aware of the students when they are using appropriate behaviour and acknowledge this, not just focus on inappropriate behaviours. Rules should be stressed and the need to follow them discussed. Reinforcement should be used, such as rewarding on-task students regularly or using a specific points system. Teachers should make clear their expectations about student behaviour.

Negotiated rules, informing parents of the rules and stressing student achievement and positives were seen as contributing significantly to the reduction of inappropriate behaviour in class. As well teachers had to work towards creating a safe and positive environment which they could do by: giving students responsibilities in the class; listening to criticisms from students; teaching appropriate behaviour; applying consequences consistently; ensuring students understood the importance of antecedents and consequences when behaviour problems were discussed; redirecting the student when inappropriate behaviours were used. Teachers had to structure the class in such a way that students developed a sense of belonging.

If the "social power" model (Alderman \& Green, 2011) is applied to the responses of the Latvian teachers it indicates that of the four types of social power, Latvian teachers suggested use of "expertness", that is helping to solve problems, taking time to engage with and actively listen to the student as a favoured strategy. As they also wanted the student to develop a sense of belonging, they supported "manipulation" which allows the student to think that 
Ilona Bruveris. Students with Behaviour Difficulties and Latvian Teacher Beliefs about them: Globalisation or Glocalisation in Action?

he/she has come up with the answer by, for example, giving the student choice and using a different tone of voice. The third type of power "coercion" was only reflected in the suggestion that a points system be used for reinforcement. This is coercive only in the sense that the teacher is in control and that this is clear to the student. They did not support strategies that involved any form of threat, which may be in line with current approaches or could also be a response to the coercion that was experienced within Soviet education. It could be linked to their beliefs about how students learn and also their belief about their role as a teacher. The fourth social power "likability" was not raised at all. "Likability" refers to students viewing a teacher as personable or fun and this increasing the prospect of co-operation with the teacher. Perhaps for teachers who had experienced the Soviet system, either as teachers or students, this was not an approach that had previously been important and formed no part of their beliefs about themselves as teachers.

\section{Conclusion}

The teacher preferred strategies indicate a close connection between Latvian teacher beliefs and the Latvian concept of pedagogy. The strategies reflect the Latvian concept of pedagogy as educating the total child rather than the art or craft of teaching. They also demonstrate teacher belief in relationship building as opposed to coercion as a means for achieving behavioural change. This could be the result of continuing an approach from Soviet times when they were told what to teach but were free to choose how and they chose to use relationships as the cornerstone of education seeing it as consistent with their beliefs about how students learn and develop. It could also be the influence of new strategies introduced through globalisation or it could be an extension of the concept of educating the total child and viewed as a strategy that would promote this by providing a role model for interaction for young people. Whatever the reason, Latvian teachers believe that building relationships is central to the management of student behaviours.

The strategies indicate that Latvian teachers share a common need with teachers elsewhere in addressing low-level but disruptive behaviours in their classrooms. As they are addressing similar needs, are there global strategies which could provide a possible solution? With the divergence in teacher beliefs about pedagogy and the strong belief in relationship building, Latvian teachers could implement strategies from elsewhere that were based on a social model for meeting the needs of students with behaviour difficulties which focussed not just on the student but sought solutions to difficulties within the total physical, social and learning environment and which corresponded to their concept of how students learned and developed. Under these circumstances they are not 
importing or accepting surrogate values rather they are demonstrating glocalisation in action by adopting and adapting strategies that help to address unfamiliar student behaviours but that also reflect their beliefs. Strategies which do not reflect current beliefs are unlikely to be implemented as they would conflict with teacher understanding of their students, school and context, thus creating additional teacher stress. For such strategies to be successfully implemented, teachers must first be taught how to identify their beliefs and understand how they affect classroom practice.

\section{References}

Alderman, G. L., \& Green, S. K. (2011). Social Powers and Effective Classroom Management: Enhancing Teacher-Student Relationships, Intervention in School and Clinic, 139-44.

Ainscow, M., \& Sandill, A. (2010). Developing inclusive education systems: the role of organisational cultures and leadership, International Journal of Inclusive Education, 14 4) 401-416.

Beaman, R. (2006). Behavioural interactions in secondary classrooms between teachers and students: what they say, what they do. PhD Thesis, Macquarie University, Australian Centre for Educational Studies, Special Education Centre.

Beaman, R., Wheldall, K., \& Kemp, C. (2007). Recent research on classroom behaviour: A review. Australasian Journal of Special Education, 31 (1), 45-60.

Brousseau, B., Book, C., \& Byers, J. (1988). Teacher beliefs and the cultures of teaching. Journal of Teacher Education, 36 (6), 33-39.

Collinson, V., Kozina, E., Lin, Y., Ling, L., Matheson, I., Newcombe, L., \& Zogla, I. (2009). Professional Development for Teachers: A World of Change, European Journal of Teacher Education, 32 (1), 3-19.

Department of Education and Science. (1989). The Elton Report. Enquiry into discipline in schools (England and Wales). London.

Erten, O., \& Savage, R. S. (2012). Moving forward in inclusive education research, International Journal of Inclusive Education, 16 (2), 221-233.

Foucault, M. (1972). The Archaeology of Knowledge; and, the Discourse on Language, trans. A. M. Sheridan Smith. New York: Pantheon Books.

Fredricks, J. A., Blumenfeld, P. C., \& Paris, A. H. (2004). School engagement: potential of the concept, state of the evidence. Review of Educational Research, 74 (1), 59-109.

Fullan, M., \& Hargreaves, A. (1991). What's Worth Fighting for in Your School? Toronto: Ontario Public School Teachers' Federation; Andover, Mass.: The Network; Buckingham, U.K.: Open University Press; Melbourne: Australian Council of Educational Administration.

Guskey, T. (2002). Professional development and teacher change. Teachers and Teaching: Theory and Practice, 8 (3/4), 381-391.

Hansen, J. H. (2012). Limits to inclusion, International Journal of Inclusive Education, 16 (1), 89-98.

Harry, B., \& Klinger, J. (2007). Discarding the deficit model. Educational Leadership 64 (5), $16-21$. 
Ilona Bruveris. Students with Behaviour Difficulties and Latvian Teacher Beliefs about them: Globalisation or Glocalisation in Action?

Infantino, J., \& Little, E. (2005).Students' perceptions of classroom behaviour problems and the effectiveness of disciplinary methods, Educational Psychology: An International Journal of Experimental Educational Psychology, 25 (5).

Kagan, D. (1992). Implications of research on teacher beliefs. Educational Psychologist, 27 (1), 65-90.

Levin, J., Nolan, J. F., Kerr, J. W., \& Elliot, A. E. (2005). Principles of classroom management: A professional decision-making model. Toronto, ON: Pearson Education Canada, Inc.

Metcalf, L. (1995). Counseling toward solutions: A practical solution-focused program for working with students, teachers and parents. West Nyack, NY: The Center for Applied Research in Education.

Nespor, J. (1987). The role of beliefs in the practice of teaching. Journal of Curriculum Studies, 19 (4), 317-328.

Reddy, L. (1999). Inclusion of disabled children and school reform: A historical perspective. In Inclusion practices with special needs students: Theory, research, and application, ed. S. Pfeiffer and L. A. Reddy, 3-24. Binghamton: Haworth Press.

Richardson, V. (1996). The role of attitudes and beliefs in learning to teach. In: J. Sikula (Ed.), Handbook of research on teaching, 102-119. New York, NY: MacMillan.

Slee, R. (2009). Beyond special and regular schooling? An inclusive education. International Studies in Sociology of Education, 18, 99-166.

Stephenson, J., Linfoot, K., \& Martin, A. J. (2000). Behaviours of concern to teachers in the early years of school. International Journal of Disability, Development and Education, $47,225-235$

Sullivan, A. M., Johnson, B., Owens, L., \& Conway, R. (2014) Punish them or engage them? Teachers' views of unproductive student behaviours in the classroom, Australian Journal of Teacher Education, 39 (6) 43-56

Tsouloupasa, C., Carsona, R., Matthews, R. M., Grawitchc, M., \& Barberd, L. (2010). Exploring the association between teachers' perceived student misbehaviour and emotional exhaustion: the importance of teacher efficacy beliefs and emotion regulation, Educational Psychology 30 (2), 173-189.

Van Swet, J., Wichers-Bots, J., \& Brown, K. (2011). Solution- focused assessment: rethinking labels to support inclusive education, International Journal of Inclusive Education, 15 (9) 909-923. 